\title{
What Are We Doing Wrong When Athletes Report Higher Levels of Fatigue From Traveling Than From Training or Competition?
}

\begin{abstract}
Julio Calleja-Gonzalez ${ }^{1 *}$, Diego Marques-Jimenez ${ }^{2}$, Margaret Jones ${ }^{2}$, Thomas Huyghe ${ }^{3}$, Fernando Navarro ${ }^{4}$, Anne Delextrat ${ }^{5}$, Igor Jukic ${ }^{6}$, Sergej M. Ostojic ${ }^{7}$, Jaime E. Sampaio ${ }^{8}$, Xavi Schelling ${ }^{9}$, Pedro E. Alcaraz ${ }^{10,11}$, Fernando Sanchez-Bañuelos ${ }^{4}$, Xavier Leibar ${ }^{12}$, Juan Mielgo-Ayuso ${ }^{13}$ and Nicolas Terrados ${ }^{14}$
\end{abstract}

\begin{abstract}
${ }^{1}$ Department of Physical Activity and Sports, University of the Basque Country, Bilbao, Spain, ${ }^{2}$ Deportivo Alavés, Academy Department, Álava, Spain, ${ }^{3}$ Catholic University San Antonio of Murcia, Murcia, Spain, ${ }^{4}$ Sport Training Lab, Faculty of Sport Sciences, University of Castilla - La Mancha, Toledo, Spain, ${ }^{5}$ Department of Sport and Health Sciences, Oxford Brookes University, Oxford, United Kingdom, ${ }^{6}$ Faculty of Kinesiology, University of Zagreb, Zagreb, Croatia, ${ }^{7}$ Faculty of Sport and Physical Education, University of Novi Sad, Novi Sad, Serbia, ${ }^{8}$ Research Center in Sports Sciences, Health Sciences and Human Development (CIDESD), University of Trás-os-Montes e Alto Douro (UTAD), Vila Real, Portugal, ${ }^{9}$ Institute of Sport, Exercise and Active Living, College of Sport and Exercise Science, Victoria University, Melbourne, VIC, Australia, ${ }^{10}$ Research Center for High Performance Sport, Catholic University of Murcia, Murcia, Spain, ${ }^{11}$ Faculty of Sport Sciences, Catholic University of Murcia, Murcia, Spain, ${ }^{12}$ Spanish Olympic Committee, Madrid, Spain, ${ }^{13}$ Department of Biochemistry Molecular Biology and Physiology, Faculty of Health Sciences, Campus de Soria, University of Valladolid, Soria, Spain, ${ }^{14}$ Regional Unit of Sports Medicine, Aviles and Health Research Institute of the Principality of Asturias (ISPA), Oviedo, Spain
\end{abstract}

Edited by:

Keywords: fatigue, competition, sport, TRIP, training, travel, recovery

Performance at the elite level in running-based team sports requires outlining the cyclical nature in which physiological and biomechanical loads lead to adaptation of the biological system as a whole (Vanrenterghem et al., 2017). Very commonly, there are congested fixture periods that seem to have no effect on physical activity, technical performance, and injury incidence (Dellal et al., 2015) injury rates or patterns (Carling et al., 2016), but do seem to decrease tactical performance, as measured by levels of movement synchronization (Folgado et al., 2015).

A very high traveling frequency is required to compete in elite professional sport. For example, the National Basketball Association's regular season consists of 82 games ( 41 home, 41 away) played over a 6-month period (Sampaio et al., 2015). This can have consequences for both physiological and psychological status and has the potential to impair performance, as seen in common anecdotal elite basketball player reports stating: "I want to sleep," "I didn't sleep enough," "I slept poorly," "I get tired of traveling"; "I prefer to sleep at home even if it means getting home late."

The sentiments and feelings like the aforementioned may clearly affect the balance between happiness and wellness (Calleja-Gonzalez et al., 2018). In that way, coaches focus on respecting, valuing, involving, engaging in dialogue with, listening to, and supporting players, as well as treating them as human beings, giving them the confidence and feelings of responsibility to try (Barker-Ruchti et al., 2014). There is a clear need for more research in this area, although some advances were already made by examining empathy using qualitative methods and identifying factors of empathy between athletes and coaches (David and Larson, 2018). Furthermore, a period of constructive reflection considering the relationship between performance analysis and recovery is strongly recommended (Calleja-González et al., 2018). Thus, there is a gap between research and reality (Buchheit, 2017), because players express that they are more fatigued from traveling than from training or competition, which is the focus of this letter.

A shift in the approach to sports performance research seems to be necessary. For example, sleep quality and quantity (Gupta et al., 2017), burden associated to traveling (Fowler et al., 2014), chronobiological disturbance (Drust et al., 2005) are often cited as limiting factors of performance in high level sport, and their impact should be considered 
and assessed. Further, the additive effect or the means by which one factor influence another should be taken into account (Tobias et al., 2013).

Elite athletes are exposed to substantial training loads (Soligard et al., 2016), however, that is only a (small) part of the key determinants of performance. Current trends in expertise describe the concept as a dynamically varying relationship captured by the constraints of the environment and those of the performer of a task (McGuckian et al., 2018). Using this approach, the context is key and should not be detached from the content, thus, the guidelines for designing and implementation of a training program will benefit from incorporating environmental information, integrated periodization, mental performance, skill acquisition, or nutrition (Mujika et al., 2018). In addition, using the aforementioned methods in combination with athlete monitoring of training, competition and psychological load, and pooled with assessments of recovery, well-being, and illness (Schwellnus et al., 2016). It may enable the achievement of enhanced performance levels.

Since extended traveling is common in elite sport (Flatt et al., 2019), it is recommended that coaches and applied sports scientists consider the following key points in order to minimize injury risk, enhance recovery, optimize performance and reduce the effect of traveling and sleep disturbance on performance with elite team sports players (Vitale et al., 2019):

- Monitoring external training load (before, during and after competition) using tracking systems (Fox et al., 2017) with the least possible invasion.

- Monitor Internal responses using heart rate measures and biomarkers in blood, saliva, and/or urine before, during and after competition (Halson, 2014).

- Monitor daily sleep quality, sleep duration, and player wellbeing to inform same day adjustments to training and competition workload (Fox et al., 2019).

- Arrive early to competition destination in order to include sufficient time on-site to recover from traveling and adjust to new time-zones, altitudes, climates, and environments (Lastella et al., 2019).

- Avoid environmental changes because changing physical sleep environments may increase susceptibility to altered sleep responses, which may negatively affect performance (Pitchford et al., 2017).

- Develop and apply consistent strategies (pre, during and posttraveling) that may help prevent or ease jet lag (Fowler et al., 2014).

- Develop and apply an ad-hoc nutrition plan for traveling (Halson et al., 2019).

Stress on the body is probably cumulative (Issurin, 2009). Therefore, the development of new variables, such as ratios, that might relate player's fatigue, training demands, match performance, environmental conditions, at home or away, could be an interesting open window to explore. Further, the creation and validation of a travel fatigue scale would enhance an understanding of the traveling effect. Also, a scale of mental fatigue (Russell et al., 2019) that informs about the stress derived from training, competition and environmental stress would be most useful.
With the increasing popularity of sport, number of contests, and travel demands on the rise, the importance of athlete load monitoring in combination with nutritional programming, implementation of recovery methods, and proper sleep practices cannot be underestimated. Taking these steps will make for a more effective travel experience and support athlete health and playing career longevity. In the same way, rationalizing the use of measurement instruments and procedures seems also a need, as anecdotally suggests that "strict data-led regimes undermine trust and stifle creativity, shackling a player's natural empathy with the game," thus, "it is vital that those who oversee performance in elite sport consider the consequences on players of such intense surveillance."

Finally, novel scientific studies examining the impact of air traveling direction, flight time, flight duration, average flight altitude (above sea level), frequency and magnitude of height changes during flight, air cabin conditions, oxygen saturation levels, and athlete chronotype are warranted to help painting a clearer picture on how different stressors impact wellness and performance due to traveling. Athlete monitoring tools may help to understand how each of the above-mentioned variables play a role on the accumulation of both acute and chronic fatigue in elite athletes. However, common wearable technologies and test procedures may still present a burden in terms of practicality, time efficiency, reliability, and/or validity. Therefore, novel easy-to-use methodologies such as the critical fusion threshold (Clemente-Suarez and Diaz-Manzano, 2019) and Ruler Test (Eckner et al., 2015; van Schooten et al., 2019) may facilitate our ability to measure and monitor the rigors of traveling on a daily basis, specifically pertaining to its consequences on the central nervous system and psychophysics in elite athletes. However, further research and clinical trials are needed to validate its applicability. Additional topics should be considered in future researches and practical solutions such as:

- Bus/plane traveling (seats ergonomic, number of disposable seats in bus/plane) (Menegon et al., 2019).

- Seating positions/dangerous seating positions (players education and control).

- Muscle activation during traveling (Smulders et al., 2019).

- Intellectual activity during traveling.

- Problem with sleep medicaments (hypotonic effects) (DeKosky and Williamson, 2020).

- Sleep banking between travels and games (Roy and Forest, 2018).

- Designing individual players traveling profile.

- Plane/bus vibration effect on athlete's bodies (Blake et al., 2018).

- Plane/bus engine noise stressor effect (Hede, 2017).

\section{AUTHOR CONTRIBUTIONS}

JC-G: original idea and conception and design. DM-J: analysis and interpretation. MJ and JS: critically reviewed. TH, FN, $\mathrm{AD}$, IJ: drafting the paper. SO, PA, and NT: final approval. XS and JM-A: approved the final version. FS-B and XL: interpretation. All authors listed have made a substantial, direct and intellectual contribution to the work, and approved it for publication. 


\section{REFERENCES}

Barker-Ruchti, N., Barker, D., and Annerstedt, C. (2014). Techno-rational knowing and phronesis: The professional practice of one middle-distance running coach. Reflect. Pract. 15, 53-65. doi: 10.1080/14623943.2013. 868794

Blake, D. F., Crowe, M., Mitchell, S. J., Aitken, P., and Pollock, N. W. (2018). Vibration and bubbles: a systematic review of the effects of helicopter retrieval on injured divers. Diving Hyperb. Med. 48, 235-240. doi: 10.28920/dhm48.4. 241-251

Buchheit, M. (2017). Houston, we still have a problem. Int. J. Sports Physiol. Perform. 12, 1111-1114. doi: 10.1123/ijspp.20 $17-0422$

Calleja-González, J., Mielgo-Ayuso, J., Sampaio, J., Delextrat, A., Ostojic, S. M., Marques-Jiménez, D., et al. (2018). Brief ideas about evidence-based recovery in team sports. J. Exerc. Rehabil. 14, 545-550. doi: 10.12965/jer.183 6244.122

Calleja-Gonzalez, J., Terrados, N., Martin-Acero, R., Lago-Penas, C., Jukic, I., Mielgo-Ayuso, J., et al. (2018). Happiness vs. Wellness during the recovery process in high performance sport. Front. Physiol. 9:1598. doi: $10.3389 /$ fphys.2018.01598

Carling, C., McCall, A., Le Gall, F., and Dupont, G. (2016). The impact of short periods of match congestion on injury risk and patterns in an elite football club. Br. J. Sports Med. 50, 764-768. doi: 10.1136/bjsports-2015095501

Clemente-Suarez, V. J., and Diaz-Manzano, M. (2019). Evaluation of central fatigue by the critical flicker fusion threshold in cyclists. J. Med. Syst. 43:61. doi: 10.1007/s10916-019-1170-3

David, S., and Larson, M. (2018). Athletes' perception of athletic trainer empathy: how important is it? J. Sport. Rehabil. 27, 8-15. doi: 10.1123/jsr.20 16-0085

DeKosky, S. T., and Williamson, J. B. (2020). The long and the short of benzodiazepines and sleep medications: short-term benefits, long-term harms? Neurotherapeutics. doi: 10.1007/s13311-019-00827-z. [Epub ahead of print].

Dellal, A., Lago-Peñas, C., Rey, E., Chamari, K., and Orhant, E. (2015). The effects of a congested fixture period on physical performance, technical activity and injury rate during matches in a professional soccer team. Br. J. Sports. Med. 49, 390-394. doi: 10.1136/bjsports-2012-091290

Drust, B., Waterhouse, J., Atkinson, G., Edwards, B., and Reilly, T. (2005). Circadian rhythms in sports performance-an update. Chronobiol. Int. 22, 21-44. doi: 10.1081/CBI-200041039

Eckner, J. T., Richardson, J. K., Kim, H., Joshi, M. S., Oh, Y. K., and AshtonMiller, J. A. (2015). Reliability and criterion validity of a novel clinical test of simple and complex reaction time in athletes. Percept. Mot. Skills 120, 841-859. doi: 10.2466/25.15.PMS.120v19x6

Flatt, A. A., Howells, D., and Williams, S. (2019). Effects of consecutive domestic and international tournaments on heart rate variability in an elite rugby sevens team. J. Sci. Med. Sport 22, 616-621. doi: 10.1016/j.jsams.2018. 11.022

Folgado, H., Duarte, R., Marques, P., and Sampaio, J. (2015). The effects of congested fixtures period on tactical and physical performance in elite football. J. Sports. Sci. 33, 1238-1247. doi: 10.1080/02640414.2015. 1022576

Fowler, P., Duffield, R., and Vaile, J. (2014). Effects of simulated domestic and international air travel on sleep, performance, and recovery for team sports. Scand. J. Med. Sci. Sports. 25, 441-451. doi: 10.1111/sms. 12227

Fox, J. L., Scanlan, A. T., and Stanton, R. (2017). A review of player monitoring approaches in basketball: current trends and future directions. J. Strength Cond Res. 31, 2021-2029. doi: 10.1519/JSC.00000000000 01964

Fox, J. L., Scanlan, A. T., Stanton, R., and Sargent, C. (2019). Insufficient sleep in young athletes? Causes, consequences, and potential treatments. Sports Med. doi: 10.1007/s40279-01901220-8. [Epub ahead of print].
Gupta, L., Morgan, K., and Gilchrist, S. (2017). Does elite sport degrade sleep quality? A systematic review. Sports Med. 47, 1317-1333. doi: 10.1007/s40279-016-0650-6

Halson, S. L. (2014). Monitoring training load to understand fatigue in athletes. Sports Med. 44(Suppl. 2), S139-S147. doi: 10.1007/s40279-0140253-z

Halson, S. L., Burke, L. M., and Pearce, J. (2019). Nutrition for travel: from jet lag to catering. Int. J. Sport Nutr. Exerc. Metab. 29, 228-235. doi: 10.1123/ijsnem.2018-0278

Hede, A. J. (2017). Using mindfulness to reduce the health effects of community reaction to aircraft noise. Noise Health. 19, 165-173. doi: 10.4103/nah.NAH_106_16

Issurin, V. B. (2009). Generalized training effects induced by athletic preparation. A review. J. Sports Med. Phys. Fitness 49, 333-345.

Lastella, M., Roach, G. D., and Sargent, C. (2019). Travel fatigue and sleep/wake behaviors of professional soccer players during international competition. Sleep Health 5, 141-147. doi: 10.1016/j.sleh.2018. 10.013

McGuckian, T. B., Cole, M. H., Jordet, G., Chalkley, D., and Pepping, G. J. (2018). Don't Turn Blind! The relationship between exploration before ball possession and on-ball performance in association football. Front. Psychol. 9:2520. doi: 10.3389/fpsyg.2018.02520

Menegon, L. D. S., Vincenzi, S. L., Andrade, D. F., Barbetta, P. A., Vink, P., and Merino, E. A. D. (2019). An aircraft seat discomfort scale using item response theory. Appl. Ergon. 77,1-8. doi: 10.1016/j.apergo.2018. 12.015

Mujika, I., Halson, S., Burke, L. M., Balague, G., and Farrow, D. (2018). An integrated, multifactorial approach to periodization for optimal performance in individual and team sports. Int. J. Sports Physiol. Perform. 13, 538-561. doi: 10.1123/ijspp.2018-0093

Pitchford, N. W., Robertson, S. J., Sargent, C., Cordy, J., Bishop, D. J., and Bartlett, J. D. (2017). Sleep quality but not quantity altered with a change in training environment in elite Australian rules football players. Int. J. Sports Physiol. Perform. 12, 75-80. doi: 10.1123/ijspp.20160009

Roy, J., and Forest, G. (2018). Greater circadian disadvantage during evening games for the National Basketball Association (NBA), National Hockey League (NHL) and National Football League (NFL) teams travelling westward. J Sleep Res. 27, 86-89. doi: 10.1111/jsr.12565

Russell, S., Jenkins, D., Smith, M., Halson, S., and Kelly, V. (2019). The application of mental fatigue research to elite team sport performance: new perspectives. J. Sci. Med. Sport 22, 723-728. doi: 10.1016/j.jsams.2018. 12.008

Sampaio, J., McGarry, T., Calleja-González, J., Sáiz, S. J., Schelling i del Alcázar, X., and Balciunas, M. (2015). Exploring game performance in the national basketball association using player tracking data. PLOS ONE 10:e0132894. doi: 10.1371/journal.pone.0132894

Schwellnus, M., Soligard, T., Alonso, J. M., Bahr, R., Clarsen, B., Dijkstra, H. P., et al. (2016). How much is too much? (Part 2) International Olympic Committee consensus statement on load in sport and risk of illness. Br. J. Sports Med. 50, 1043-1052. doi: 10.1136/bjsports-2016096572

Smulders, M., Naddeo, A., Cappetti, N., van Grondelle, E. D., Schultheis, U., and Vink, P. (2019). Neck posture and muscle activity in a reclined business class aircraft seat watching IFE with and without head support. Appl. Ergon. 79, 25-37. doi: 10.1016/j.apergo.2018. 12.014

Soligard, T., Schwellnus, M., Alonso, J. M., Bahr, R., Clarsen, B., Dijkstra, H. P., et al. (2016). How much is too much? (Part 1) International Olympic Committee consensus statement on load in sport and risk of injury. Br. J. Sports. Med. 50, 1030-1041. doi: 10.1136/bjsports-2016096581

Tobias, G., Benatti, F. B., de Salles Painelli, V., Roschel, H., Gualano, B., Sale, C., et al. (2013). Additive effects of beta-alanine and sodium bicarbonate on upper-body intermittent performance. Amino Acids 45, 309-317. doi: 10.1007/s00726-013-1495-z 
van Schooten, K. S., Duran, L., Visschedijk, M., Pijnappels, M., Lord, S. R., Richardson, J., et al. (2019). Catch the ruler: concurrent validity and test-retest reliability of the ReacStick measures of reaction time and inhibitory executive function in older people. Aging Clin. Exp. Res. 31, 1147-1154. doi: 10.1007/s40520-0181050-6

Vanrenterghem, J., Nedergaard, N. J., Robinson, M. A., and Drust, B. (2017). Training load monitoring in team sports: a novel framework separating physiological and biomechanical load-adaptation pathways. Sports Med. 47, 2135-2142. doi: 10.1007/s40279-0170714-2

Vitale, K. C., Owens, R., Hopkins, S. R., and Malhotra, A. (2019). Sleep hygiene for optimizing recovery in athletes: review and recommendations. Int. J. Sports Med. 40, 535-543. doi: 10.1055/a-0905-3103
Conflict of Interest: DM-J was employed by company Deportivo Alavés, Spain.

The remaining authors declare that the research was conducted in the absence of any commercial or financial relationships that could be construed as a potential conflict of interest.

Copyright (c) 2020 Calleja-Gonzalez, Marques-Jimenez, Jones, Huyghe, Navarro, Delextrat, Jukic, Ostojic, Sampaio, Schelling, Alcaraz, Sanchez-Bañuelos, Leibar, Mielgo-Ayuso and Terrados. This is an open-access article distributed under the terms of the Creative Commons Attribution License (CC BY). The use, distribution or reproduction in other forums is permitted, provided the original author(s) and the copyright owner(s) are credited and that the original publication in this journal is cited, in accordance with accepted academic practice. No use, distribution or reproduction is permitted which does not comply with these terms. 